\title{
EFL Students' Speaking Achievement And Its Relationship With Epistemic Beliefs
}

\author{
Kholifatur Rohmah, kholifaturrohmah550@gmail.com, Universitas Brawijaya, \\ Malang, Indonesia \\ Ive Emaliana, ive@ub.ac.id, Universitas Brawijaya, Malang, Indonesia
}

\begin{abstract}
The purpose of the present research is to uncover the relationship between English as a Foreign Language (EFL) students' speaking score achievement and their epistemic beliefs. To this end, 63 Indonesian EFL students completed two different instruments, namely the EFL epistemic beliefs questionnaire and the final test of the Intensive Speaking course. The results of Pearson Product Moment Correlation demonstrated that speaking achievement is significantly correlated with epistemic beliefs adapted from (Emaliana, 2017), consisting of six sub-dimensions, namely, fixability, certain knowledge, omniscient authority, learning and communication strategies, foreign language aptitude, and motivation and expectation. Likewise, the findings manifested that students who are indicated by a high level of epistemic beliefs (sophisticated students) outperform simple students, who are otherwise having a low level of epistemic beliefs. This research holds significant implications for curriculum, teaching and learning materials, and instructional media developers, as well as teachers to afford students with personal beliefs about knowledge and knowing EFL to enhance the students' speaking skills.
\end{abstract}

Keywords: Epistemic beliefs, Achievement, Speaking, EFL

\section{A. INTRODUCTION}

To communicate eloquently with each other is the most indispensable function of language for human beings. First, people need to comprehend the language utilized among them to communicate their aims and messages, so communication is a basic skill in language arts, as it is a rudimentary device for passing on facts, perceptions, impressions, concepts, and beliefs. Furthermore, this implicates that speaking, long before writing or reading, is the first step of language learning, notwithstanding when learning a foreign language like English. As postulated by (Schneider et al., 2016), the speaking ability is categorized as the main skill that students should be mastered when they are learning a foreign language. They also state that mastering speaking effectively is the core point in learning a new language. Other skills like writing and reading are equivalently significant in elaborated language use, for they improve rhetoric and understanding, but speaking requires priority (Lazaraton, 2001).

Speaking skill consists of accuracy and fluency which need to be mastered by EFL learners. As one of the study programs in university, the English as language teaching department requires the students to be fluent and accurate, as they will become future English teachers that need to be fluent in delivering English materials through speaking. Indonesian Higher Education especially English Language Teaching (ELT) study program implements competency-based language instruction method in the teaching of speaking; however, in the daily life, most of Indonesian EFL students do not speak English, they only can practice their English in EFL classroom (Marcellino \& Marcellinus, 2005). Since they lack practices, it can be presumed that the students may face several issues in the EFL classroom (Mahmud \& Saputra, 2018). Therefore, in the ELT study 
program, speaking competence can be achieved by joining several courses that accommodate students' improvement of speaking achievement such as General English Communication, Guided Speaking, Intensive Speaking, and Public Speaking courses. Furthermore, knowing the factors which are important to facilitate a good process of obtaining speaking competence, students' characteristics related to various factors attached to the students are unique. By identifying the significant factors affecting speaking competence, a good process of learning is facilitated.

These speaking issues are affected by several factors such as lack of motivation, interlanguage, and speaking anxiety. Besides, as defined by Emaliana et al., (2018) and Puspitasari et al., (2019), based on achievement and performance, general foreign language anxiety and specific English skills also cause a negative effect. Therefore, better ways to avoid that issue could directly qualify for better representation of speaking achievement. In fact, many recent researchers have come up with their ideas that motivational elements play an important role in the learning process, especially in behavioral and cognitive parts. Epistemic beliefs are defined as a person's beliefs related to knowledge and knowledge (Ketabi et al., 2014). Besides, many studies conducted by Indonesian EFL researchers revealed that the anxiety issues were found to hinder students' motivation and performance since the students appear to stay away from any taking chance section during the learning process which leads them to not be able to improve their language learning in the classroom (I. Emaliana and Rahmiati 2019; Rahmiati et al. 2019). Therefore, the awareness of how epistemic beliefs differences level and speaking achievement of each student related to learning strategies are correlated each other in the learning process of the speaking class can give a chance for students to reduce their speaking problems and the implementation of EFL speaking in higher education will successfully implement in the compulsory subjects of ELT program.

The afore-mentioned speaking problems appeared can be affected by students' behavior and even c beliefs. According to Ketabi et al., (2014), epistemic beliefs refer to the person's beliefs related to knowledge and knowing. Emaliana, (2017) mentions that personal epistemic beliefs involve the nature of knowledge and the nature of knowledge. Besides, Puspitasari et al., (2019) add that the nature of knowledge is well explained through representations of justification of knowledge and source of knowledge, whereas the nature of knowledge consists of the simplicity of knowledge and certainty of knowledge. Further, in line with Rahmiati et al., (2019), some researchers have studied the relationship between epistemic beliefs and behavioral and motivational strategies. Those studies indicated that there was a relationship between students' various characteristics and academic achievement.

Emaliana et al., (2018) also say that epistemic beliefs are closely related to cognition and academic achievement because they can build up motivation in learning, particularly depend on students' beliefs of knowledge and knowing. As every student is unique, each of them will have their own characteristics. The students' different kinds of characteristics will also come up with different epistemic beliefs which are categorized into simple or sophisticated. Priani W \& Vianty, (2004) explain that epistemic beliefs include the nature of knowledge and how knowledge brings effects to the learning and teaching process. Emaliana, (2017) put some aspects to categorize EFL students' epistemic beliefs levels, those are students' perception about EFL learning and the ways of how to learn EFL itself. Students who are categorized into sophisticated have several characteristics, as follows: when they have certain knowledge which admits EFL learning approaches are evolving; they perceive more than just as simple knowledge, but EFL learning is based on complex theories, so many approaches can be employed; they have dynamic fixability, which possess paradigm that people's ability to learn EFL can improve over time; they have a positive perception on omniscient authority, which allow them to learn EFL through reason or logic experiences that can be done individually by 
everyone; they believe people who acquire a new language in younger ages and learn more than one new languages have better foreign language aptitude; they have active learning and communication strategies by practicing more and make use contexts for learning EFL, and they are motivated to learn EFL for better future and are expected to know more foreign people and culture.

On the other hand, students who are categorized into simple have several characteristics, as follows: simple category of epistemic beliefs refer to students who have certain knowledge that is EFL learning approaches are unchanging; they believe in simple knowledge, so EFL learning is facts, and only particular approaches can be employed for learning to occur; they have static fixability, which own principle that people's ability to learn EFL is inherited and cannot improve over time; they have negative perception on omniscient authority, which make them think that learning EFL is handed down by authorities; they believe people who acquire new language in younger ages and learn more than one new languages do not always have better foreign language aptitude; they have less active learning and communication strategies, so they neither practice more nor make use contexts for learning EFL; and they are motivated to learn EFL for better future and are expected to know more foreign people and culture. Thus, EFL epistemic beliefs depend on personal thoughts to define some factors related to EFL learning perception.

Furthermore, Ive \& Lailiyah, (2018)'s study adds two types of students based on their epistemic beliefs category. Students with a high level of epistemic beliefs (sophisticated ones) learn EFL through process-oriented learning which allows students to have a lot of exercises and training. In contrast, students with simple epistemic beliefs acquire the EFL learning process by utilizing ready-to-use materials that are provided by people who get the authority to teach, like teachers. Also, students with sophisticated epistemic beliefs learn English by exploring problems and finding solutions, meanwhile, students with simple epistemic beliefs learn English by receiving provided materials more.

It is generally agreed that every student who is learning EFL holds a different epistemic beliefs category. Because these beliefs influence students to handle and use knowledge in the process of learning EFL, they play important role in the students' thinking (Ngai-Man et al., 2011). Knowing students' English achievement level in speaking means indirectly knowing the degree of the students' process of learning EFL, which indicates how the students define and construct knowledge effectively about speaking skill. Thus, students' epistemic beliefs play paramount roles to shape students' speaking achievement as the students' views about the nature of knowledge and knowing the effect on their ways to learn EFL. Students own different epistemic beliefs about how speaking in the English language is learned. These beliefs are influenced by students' previous positive or negative experiences as language learners (Richardson \& T, 2013), students' cultural background (Chen A, 2012), family background (Davies et al., 2004), and individual differences such as personality (Ngai-Man et al., 2011). Not to mention when EFL students learn the English language, particularly speaking ability, epistemic beliefs contribute to their speaking achievement level. Accordingly, speaking achievement in an EFL setting is dependent on epistemic beliefs, so more specifically, this present study is guided by the research question, namely "Is there any statistically significant relationship between EFL students' epistemic beliefs and their speaking achievement?" By conducting this research, it is expected several significances as follow. Practically, the significance of this present study will contribute to speaking lecturers. They can be more aware of students' individual differences which become factors influencing learning. Theoretically, this research is aimed at becoming references for future research related to epistemic beliefs and English language learning contexts such as research about teaching techniques, methods, media, and materials that accommodate the learning atmosphere to enhance students' achievement in speaking class. 


\section{B.METHOD}

In this research, the writers applied a quantitative approach to answer the research question. The numerical data was expected to be the answer to find out the relationship between two variables (Creswell, 2012), so the correlational study is the appropriate research method. According to Arikunto, (2006), a correlational study aims at finding out whether there is a significant correlation between two variables. In this study, the variables were students' epistemic beliefs and speaking achievement. Those data were obtained from the EFL epistemic beliefs questionnaire that was distributed to the students and the mid-term test scores of the Intensive Speaking class.

There are two research instruments to measure two variables, namely students' EFL epistemic beliefs questionnaire and the mid-term test scores. The questionnaire was adopted from Emaliana, (2017), was close-ended, using a 4-point Likert-type rating scale from strongly disagree (1) to strongly agree (4), and it consisted of six sub-dimensions, namely, fixability, certain knowledge, omniscient authority, learning and communication strategies, foreign language aptitude, and motivation and expectation. From the tryout, there were 35 questionnaire items were valid, and after calculating its reliability, the results were as follows: certain knowledge $(\alpha=.327)$, fixability $(\alpha=.487)$, foreign language aptitude $(\alpha=.402)$, learning and communication strategies $(\alpha=.564)$, motivation and expectation $(\alpha=.690)$, omniscient authority $(\alpha=.349)$. Those 35 items were representing six sub-dimensions constructing EFL epistemic beliefs instrument. Students with simple epistemic beliefs levels were indicated by score 35-70, meanwhile, students with sophisticated epistemic beliefs levels were indicated by score $71-140$.

The second instrument was speaking mid-term test scores to reveal the other variable, namely speaking achievement. This mid-term test scores were chosen because the test was aimed at showing the EFL students' achievement level to produce short oral discourses in the form of dialogue and monologues regarding social interaction in daily life with a focus on understanding key ideas, the ability to search for keywords, and on the introduction of diverse accents from various English speakers.

There were several research procedures administered to take the data needed. Firstly, to have the speaking achievement score, the procedure was asking information to the head of the English education department about speaking test administration. After knowing that the test was made together with the lecturers under one lecturer-coordinator, the researchers asked the coverage of the speaking test. The speaking test consisted of four micro-skills to measure, namely fluency and coherence, lexical resources, grammatical range and accuracy, and pronunciation. Next, the researchers asked permission from the lecturers to allow them to obtain the speaking test scores. It was found out that only one lecturer allowed to give the speaking test scores and the access to meet the students in 20 minutes of the class time for EFL epistemic beliefs questionnaire distribution. After that, the researchers went to the scheduled time of each speaking class for 20 minutes before the class ended. The researchers explained the purposes of the questionnaire distributions and asked the participants to fill in consent form agreements for voluntary participation. There were only 63 students who joined the research out of 105 second-year students who took Intensive Speaking course who were coming from three different class groups. The volunteered participants were given some incentive in the form of e-money. Next, the researchers were present in the EFL epistemic beliefs distributions. Instructions to fill in the paper of the questionnaires were read and each item of the questionnaire was read when the participants filled in the responses. 
Data analysis was done in three steps. Firstly, obtaining the participants' results of speaking achievements from the lecturer. Secondly, analyzing the participants' category of EFL epistemic beliefs. This was done by calculating each participant's responses to questions in the EFL epistemic beliefs questionnaire. Each response to strongly disagree was 1, disagree was 2 , agree was 3 , and strongly disagree was 4 . The total score of each participant showed their category of EFL epistemic beliefs. Thirdly, analyzing the relationship between students' EFL epistemic beliefs and their speaking achievement by using dependent sample T-test in SPSS version 20. Person Product Moment correlation was done not only to confirm the results of the correlation but also to see the predictive relationship between EFL students' epistemic beliefs level and their speaking ability.

\section{C.RESULTS AND DISCUSSION}

In relation to the correlation between EFL epistemic beliefs and English language proficiency, there are several findings using descriptive statistics as follows. The results of the EFL epistemic beliefs questionnaire revealed that among 63 participants, they were spread out into one category, namely sophisticated with various ranges of scores. It meant that they believed that learning English, especially for mastering speaking skills was best done through a communicative approach where the language is a means of communication. Learning through context, systematic language functions with meaningful tasks and various communicative strategies become the most important activities.

The findings show that the correlation between two variables which are EFL Students' Epistemic Beliefs and speaking achievement does not indicate a high correlation as shown in table 1 below, but still the relationship is significant.

Table 1. Correlation between Epistemic Beliefs and Speaking Achievement.

\begin{tabular}{|c|c|c|c|}
\hline \multicolumn{4}{|c|}{ Correlations } \\
\hline & & EB & Test \\
\hline \multirow[t]{3}{*}{$\overline{\mathrm{EB}}$} & Pearson Correlation & 1 & $.487^{* *}$ \\
\hline & Sig. (2-tailed) & & .000 \\
\hline & $\mathrm{N}$ & 63 & 63 \\
\hline \multirow[t]{3}{*}{ Test } & Pearson Correlation & $.487^{* * *}$ & 1 \\
\hline & Sig. (2-tailed) & .000 & \\
\hline & $\mathrm{N}$ & 63 & 63 \\
\hline
\end{tabular}

As depicted in table 1, the correlation coefficient between EFL students' epistemic beliefs and speaking achievement is .487 categorized as having a medium correlation as the correlation is considered significant at the 0.01 level. While the P-value was $.000<0.01$ which shows that the two variables show significant correlation. Previously, the writer presented two hypotheses, particularly, the null hypothesis $(\mathrm{H} 0)$ and the alternative hypothesis $(\mathrm{H} 1)$. $\mathrm{H} 0$ is stated as that there is no correlation between EFL students' epistemic beliefs and speaking achievement.

Meanwhile, H1 was postulated as there is a correlation between EFL students' epistemic beliefs and speaking ability. Since the result shows that there is a positive correlation, with the medium correlation between EFL students' epistemic beliefs and their speaking achievement, the null hypothesis (H0) is rejected and thus, the alternative hypothesis (H1) is accepted.

This positive and medium correlation, however, brings some benefits to the pedagogical practices, especially, when epistemic beliefs are discussed thoroughly based on 
the correlation results. These epistemic beliefs have six dimensions which are certain knowledge, fixability, omniscient authority, foreign language aptitude, learning and communication strategies, and motivation and expectation. Those dimensions were expanded into 35 items which were provided in the questionnaire. The responses varied in option "YES" and "NO".

The certain knowledge dimension was translated into item numbers 1, 2, 3, and 4. Based on the result of the questionnaire, it is found that the highest mean score belongs to the number $3(\mathrm{M}=1.88)$. It is shown that most of the students might really understand the function of learning English itself for their future. The lowest means score belongs to item number $1(\mathrm{M}$ $=1.03$ ). It contains a negative statement which shows the respondents' thought that to learn English means different things to different students, students might have their own learning styles or strategies to learn English.

The fixability dimension was translated into item number 5, 6, 7, 8, 9, 10. It is found from the scored questionnaire that the highest mean score belongs to item number $7(\mathrm{M}=$ 1.43). Most of the students are agree that going over a difficult textbook chapter that is written in English usually will not help them to understand the materials. The lowest mean score belongs to item number $5(\mathrm{M}=1.05)$. It contains a negative statement that shows that students can decide whether they use more of a textbook or not based on their needs when learning English. The omniscient authority dimension was translated into item number 12, 13, 14, and 15. The result of the questionnaire shows that the highest score belongs to item number 13 $(\mathrm{M}=1.88)$. It is shown that most of the students are agree that lecturers should teach their students all there is to know about learning English. Meanwhile, the lowest score belongs to item number $14(\mathrm{M}=1.12)$. It is shown that students who question their lecturers' lectures are not troublemakers.

The simple knowledge was translated into item number 16, 17, 18, 19, 20, 21, and 22. According to the result of the questionnaire, it is found that the highest mean score belongs to item number $20(\mathrm{M}=1.73)$. It means that most of the students are agree that learning definitions word-for-word is often necessary to do well on English tests. The lowest score belongs to item number $16(\mathrm{M}=1.33)$. This item can be assumed that students do not like to watch movies that use English but do not have an ending.

The foreign language aptitude dimension was translated into item number 23, 24, 25, and 26. Based on the result, it is found that the highest mean score belongs to item number $23(\mathrm{M}=1.80)$. It means that most of the students are agree that it is easier for children than adults to learn English. The lowest score belongs to item number $25(\mathrm{M}=1.18)$. This item can be assumed that whether women or men have an equal chance to be a success in learning English.

The learning and communication strategies dimension was translated into item number $27,28,29,30$, and 31 . The result of the questionnaire shows that the highest score belongs to item number $27(\mathrm{M}=1.98)$. It is shown that most of the students are agree that it is important to repeat and practice a lot in learning English. Meanwhile, the lowest score belongs to item number $30(\mathrm{M}=1.70)$. It is shown that students feel self-conscious to speak English as the function of a foreign language in front of other people.

The motivation and expectation dimension was translated into item number 32, 33, 34, and 35. The result of the questionnaire shows that the highest score belongs to item number $32(\mathrm{M}=1.98)$. It is shown that most of the students are likely to use English in daily life if their speaking ability is very well. Meanwhile, the lowest score belongs to item number 33 \& $34(\mathrm{M}=1.93)$. It is shown that students considered English as one of the skills that students need to master to help them get a good job in the future.

Results of the present investigation unravel similar perspective on that previous studies related to the sophistication of epistemic beliefs in science education (Chen 2012; Franco et 
al. 2012; Ive Emaliana, Gozali, and Ratri 2018), or sophistication of epistemic beliefs about literacy (Ferguson and Bråten 2013; Greene, Cartiff, and Duke 2018) predict proficiently better students. Therefore, the present study results are consistent with the general trend, that more epistemologically sophisticated students usually outperform students with simple epistemic beliefs.

Unlike the students who belonged to simple beliefs who tend to own some concepts of EFL learning is speech, language rules, language is a habit, and learners are passive, these results of the study informed that sophisticated students believed that behavioristic or audiolingual approach was not the best way when learning English especially for improving speaking ability. They also do not have concepts that EFL learning is a reflection of the human mind, language is a creative process which was explained by deep structure or surface structure, and learners were active, as they were allowed to construct tentative rules on language. The students also do not believe that the cognitive approach became the best way to learn English to improve their speaking achievement. Therefore, several characteristics of students with the high level of epistemic beliefs which are called sophisticated students showed that they owned some concepts of EFL that focus on learning a language which included language acquisition, like interlanguage, negotiation of meaning, and comprehensible input, which made the respondents believed second language acquisition (SLA) was the best approach to master speaking skill. Besides, the students had concepts of EFL that learning language was based on communication had a purpose and the use of discourse competences (socio-culture, linguistics, pragmatics, and strategic competences) (Bierbrauer and Meyer 1994). These sophisticated students believe that communicative language teaching was the best approach to learn English, especially for enhancing their speaking achievement.

Also, the results of the study can predict that the higher the students' EFL epistemic beliefs level, the better their speaking achievement. Accordingly, three pedagogical implications that relate to this prediction is offered. First, the results of the study can be the basis of developing a course profile in the ELT study program curriculum, especially to determine the course objective of speaking for the second-year students. It shows that to obtain high speaking achievement, students' way of defining learning EFL and how they should learn to improve speaking ability can be encouraged through course descriptions which are derived and generate from the results of this study, i.e., based on the communicative approach. Second, this study emphasizes that the communicative approach that is used as the basis of the teaching of speaking for the second year students require also an emphasis on fluency and coherence, lexical resources, grammatical range and accuracy, and pronunciation. Third, based on the present study, it appears that students with a higher order of thinking outperform students with a lower order of thinking skills, thus, several teaching strategies can be offered to accommodate the successful speaking achievement to students with sophisticated EFL epistemic beliefs, like encouraging active learning problem based- learning or task-based learning (Ellis 2005).

\section{CONCLUSION}

This research is intended to find the correlation between EFL students' epistemic belief and their speaking achievement. Based on the result above, the correlation coefficient .487 and $\mathrm{P}$ Values .000 , the result shows that there is a significant relationship between EFL students' epistemic beliefs and their speaking achievement. It indicates that the EFL students' epistemic beliefs will significantly contribute to their speaking achievement. Knowing the characteristic of every students' epistemic beliefs is necessary because once learners 
understand their level of EFL epistemic beliefs, they can enhance their performance in learning speaking to get a good speaking score. The findings of this study may have some pedagogical implications for lecturers as an input to make daily work, assignments, and tasks which suit the student's different level. Regarding the importance of the study, communicative strategies are expected to be used by the lecturer in teaching since most of the second-year are sophisticated learners and the strategy is suited. To sum up, it can be summarized that students with a higher degree of EFL epistemic beliefs also have a higher level of speaking proficiency.

According to this research's finding, most second-year students are sophisticated and the speaking achievement categorization was at a high level. Therefore, the researcher brings up the following suggestions: Theoretically, the result of the study can be used as a reference for future research related to the other English skill which brings up educational theories based on each type of epistemic beliefs. Since the study only focuses on the second-year students, it is possible if future research can focus on the other level of students. Since the correlation was in medium correlation, the further researcher also might develop this research by having a test to complete the requirements of speaking assessment to know the aspects of speaking assessment. Practically, according to the finding, students can be aware to reach the success of speaking performance. Then, teachers are expected in deciding on suitable learning activities to engage students who had sophisticated epistemic beliefs. In this study, teaching techniques that should be conducted by teachers should be appropriate with sophisticated students. Since the result shows that sophisticated prefer to have a commutative strategy, it can be applied in the learning process more often to help them practice learning English.

\section{E. REFERENCES}

Arikunto, S. (2006). Prosedur Penelitian Suatu Pendekatan Praktik. Rineka Cipta.

Bierbrauer, G., \& Meyer, H. (1994). Measurement of Normative and Evaluative Aspects Inindividualistic and Collectivistic Orientations. The Cultural Orientation Scale (COS), 1(8), 189-99.

Chen A, J. (2012). Implicit Theories, Epistemic Beliefs, and Science Motivation: A PersonCentered Approach. Learning and Individual Differences, 22(6), 724-35.

Creswell, J. W. (2012). Educational Research: Planning, Conducting, and Evaluating Quantitative and Qualitative Research. Cambridge University Press. https://www.cambridge.org/core/product/identifier/CBO9781107415324A009/type/book\% 0A_part

Davies, Elder, Catherine, \& Alan. (2004). The Handbook of Applied Linguistics Blackwell Publishing Blackwell Handbooks in Linguistics (Issue 17). Blackwell Publisher. https://doi.org/https://doi.org/10.1002/9780470757000.ch7.

Ellis, \& Rod. (2005). Instructed Language Learning and Task-Based Teaching. In Handbook of Research in Second Language Teaching and Learning (Issue 52). Routledge.

Emaliana, I, \& Rahmiati, I. (2019). EFL Students' Epistemic Beliefs, Learning Strategies, and Online Learning Engagement: Exploring Possible Relationship. International Seminar on Language, Education, and Culture Proceeding.

Emaliana, Ive. (2017). Correlation between EFL Epistemic Beliefs and English Language 
Proficiency among Indonesian EFL Students [Universitas Negeri Malang].

http://mulok.library.um.ac.id/index3.php/84459.html

Emaliana, Ive, Gozali, A., \& Ratri, D. P. (2018). Exploring EFL Students' Epistemic Beliefs, Metacognitive Awareness, Classroom Anxiety in Relation to English Achievement. The Fourth International Conference on English Acrros Cultures, 101.

Ferguson, Leila E, I. B. (2013). Student Profiles of Knowledge and Epistemic Beliefs: Changes and Relations to Multiple-Text Comprehension. Learning and Instruction, 25, 49-61.

Franco, M, G., Muis, K. R., Kendeou, P., Ranellucci, John, Sampasivam, L., \& Wang., X. (2012). Examining the Influences of Epistemic Beliefs and Knowledge Representations on Cognitive Processing and Conceptual Change When Learning Physics. Learning and Instruction, 1(22), 62-77.

Greene, A, J., Cartiff, B. M., \& Duke, R. F. (2018). A Meta-Analytic Review of the Relationship between Epistemic Cognition and Academic Achievement. Journal of Educational Psychology, 110(8).

Ive, E., \& Lailiyah, N. (2018). Sophisticated Beliefs: An Interpretative Phenomological Analysis of Students' Task-Based Learning Experiences. Erudio Journal of Educational Innovation, 5(1), 124-135.

Ketabi, Saeed, Zabihi, R., \& Ghadiri, M. (2014). Pre-Service English Teachers' Epistemological Beliefs and Their Conceptions of Teaching. International Journal of Research Studies in Psychology, 3(1), 3-12.

Lazaraton, A. (2001). Teaching Oral Skills. Teaching English as a Second or Foreign Language, 3(15), 103.

Mahmud, \& Saputra, Y. (2018). Tracing Back the Issue of Speaking Anxiety among EFL Learners: From Possible Causes to Practical Implications. Journal of English Language Studies, 3(2), 125.

Marcellino, \& Marcellinus. (2005). Competency-Based Language Instruction in Speaking Classes: Its Theory and Implementation in Indonesian Contexts. Indonesian JELT, 1(1), 33-44.

Ngai-Man, C., Ho, I. T., \& Ku, K. Y. L. (2011). Epistemic Beliefs and Critical Thinking of Chinese Students. Learning and Individual Differences, 21(1), 67-77.

Priani W, \& Vianty, M. (2004). The Use of English Comic Book Series in Teaching Reading Comprehension. Pustaka Jaya.

Puspitasari, I., Emaliana, I., \& Lailiyah, N. (2019). Interweaving EFL Learners' Speaking, Reading, Writing Strategies and Epistemic Beliefs to Language Achievement through ELearning. International Conference on Advances in Education, Humanities, and Language Proceeding.

Rahmiati, I. I., Emaliana, I., Khoirunnisa, R., Ju, S. B., \& Adi, S. S. (2019). EFL Epistemic Beliefs, Writing Apprehension, Writing Strategies, Writing Performance: Exploring Possible Relationships. International Conference on Advances in Education, Humanities, and Language. 
Richardson, \& T, E. J. (2013). Epistemological Development in Higher Education.” 9: . Educational Research Review, 9, 191-206.

Schneider, Jan, Börner, D., Rosmalen, P. Van, \& Specht, M. (2016). Enhancing Public Speaking Skills-an Evaluation of the Presentation Trainer in the Wild. In European Conference on Technology Enhanced Learning, 76, 263. 